REFERENCES

1 Bizzarri-Schmid MD, Desai SP. Prolonged neuromuscular blockade with atracurium. Can Anaesth Soc J 1986; 33: 209-12.

2 Naguib M, Gyasi HK, Abdulatif M, Absood GH. Rapid tracheal intubation with atracurium. A comparison of priming intervals. Can Anaesth Soc J 1986; 33: 150-6.

3 Basta SJ. Ali HH, Savarese JJ et al. Clinical pharmacology of atracurium besylate (BW 33A): a new non-depolarizing muscle relaxant. Anesth Analg 1982; 61: 723-9.

4 Miller RD, Rupp SM, Fisher DM, Cronnelly $R$, Fahey MR, Sohn YJ. Clinical pharmacology of vecuronium and atracurium. Anesthesiology 1984; 61: 444-53.

5 Hughes $R$. Atracurium-the first years. Clinics in Anesthesiology 1985; 3: 331-45.

6 Gyasi $H K$, Naguib $M$. Atracurium and severe hepatic diseuse. Can Anaesth Soc J 1985; 32: 161-4.

\section{Prolonged neuromuscular blockade with atracurium}

To the Editor:

I read with interest the case report by BizzarriSchmid and Desai entitled "Prolonged neuromuscular blockade with atracurium."1 The case suggests that peripheral nerve stimulation may be unreliable as a monitor of neuromuscular blockade, and it highlights the need for adequate assessment of recovery. However, I think that the patient received higher than usual doses of atracurium and the way the neuromuscular function was monitored was not entirely appropriate.

As far as I can ascertain from the text, the total amount of atracurium given was $135 \mathrm{mg}(2.3$ $\mathrm{mg} \cdot \mathrm{kg}^{-1}$ ), not $105 \mathrm{mg}$ as mentioned in the abstract, over 2.5 hours. This is considerably more $(0.9$ $\left.\mathrm{mg} \cdot \mathrm{kg}^{-1} \cdot \mathrm{h}^{-1}\right)$ than typical maintenance doses $(0.3-$ $\left.0.5 \mathrm{mg} \cdot \mathrm{kg}^{-1}\right){ }^{2}$ In addition, the patient received four drugs expected to potentiate neuromuscular blockade: gentamycin, d-tubocurarine, succinylcholine, ${ }^{3}$ and enflurane. However, some patients are unusually resistant to neuromuscular blockers, and relatively high doses of atracurium may be justified if proper monitoring is used.

The authors mentioned that they stimulated both ulnar and facial nerves, but they do not say which response they evaluated as a guide to administration of more relaxant. The muscles supplied by the facial nerve are more resistant to relaxants than the adductor pollicis. ${ }^{4}$ Thus, if the response to stimulation of the facial nerve is used as a guide, an overdose of a neuromuscular blocking drug may be given. In addition, it is not clear how the response was assessed. It has been shown that even trained observers can grossly overestimate the degree of response to train-of-four stimulation. ${ }^{5}$ Therefore, in the absence of recording equipment, it appears impossible to rule out the presence of fade.

More important, however, is the authors' use of tetanic stimulation. During the case, all necessary information could have been provided by the response to train-of-four stimulation, and the confounding effect of post-tetanic potentiation could have been avoided. ${ }^{6}$ More specifically, the use of tetanic stimulation is inappropriate before the administration of neostigmine, because this leads to an overestimate of neuromuscular recovery when further stimulation is applied. This could explain the apparent discrepancy between the response to peripheral nerve stimulation and clinical assessment. Similarly, there is no reason to apply tetanic stimulation before giving an additional maintenance dose of atracurium; the response to train-offour can provide adequate information.

I conclude that the prolonged weakness reported in this case was observed after large doses of atracurium, and its neuromuscular origin has not been firmly established.

François Donati PH D MD FRCPC

Department of Anaesthesia

Royal Victoria Hospital

and McGill University

Montreal, Quebec H3A 1AI

\section{REFERENCES}

1 Bizzarri-Schmid MD, Desai SP. Prolonged neuromuscular blockade with atracurium. Can Anaesth Soc J 1986; 33: 209-12.

2 Gramstad L, Lilleaasen $P$. Neuromuscular blocking effects of atracurium, vecuronium and pancuronium during bolus and infusion administration. $\mathrm{Br} \mathrm{J}$ Anaesth 1985; 57: 1052-9.

3 Stirt JA, Katz RL, Murray AL, Scheh DL, Lee C. Modification of atracurium blockade by halothane 
and by suxamethonium. Br J Anaesth 1983; 55: 71S-75S.

4 Stiffel $P$, Hameroff $S R$, Bitt $C D$, Cork RC. Variability in assessment of neuromuscular blockade. Anesthesiology 1980; 52: 436-7.

5 Viby-Mogensen, Engback J, Jensen NH, Chraemmer-Jorgensen, Ording $H$. New developments in clinical monitoring of neuromuscular transmission: monitoring without equipment. In:

"Clinical Experiences with Norcuron," edited by Agoston S, Bowman WC, Miller RD, Viby-Mogensen J. Excerpta Medica, Amsterdam, 1983, pp 63-71.

6 Ali HH, Savarese JJ. Monitoring of neuromuscular function. Anesthesiology 1976; 45: 216-49.

\section{REPLY}

The suggestion by Naguib and Gyasi that an interaction may exist between tamoxifen or danazol and atracurium is interesting and warrants further investigation. Tamoxifen is a nonsteroidal drug with strong antiestrogen properties, which are considered secondary to its ability to compete with estrogen for binding sites in target tissues. It is used in the treatment of advanced breast cancer in postmenopausal women. Tamoxifen is prepared as a tablet with carboxymethylcellulose calcium magnesium stearate, mannitol and starch as inactive ingredients.' Danazol is a synthetic androgen which suppresses the pituitary-ovarian axis, has weak androgenic activity, and possibly binds directly to gonadal steroid receptors. It is used in the treatment of endometriosis, fibrocystic breast disease and hereditar angioedema. Danazol (Danocrine) also is supplied in capsule form prepared with benzyl alcohol, gelatin, lactose, magnesium stearate, parabens, sodium propionate, starch, talc and food coloring. ${ }^{2}$

Tamoxifen and danazol both conain ring structures. bind to receptors and are prepared with magnesium stearate. The effect of the molecular structure and receptor binding ability on the interaction of these drugs and muscle relaxants merits artention. Magnesium sulfate is known to potentiate the effects of muscle relaxants. Magnesium stearate may have similar properties. Also, danazol is structurally similar to the adrenocorticoste roids which have been reported to potentiate or antagonize the effects of nondepolarizing blockers. ${ }^{4,5}$

In summary, we feel that Drs. Naguib and Gyasi inroduce an important point and we agree that atracurium and perhaps other nondepolarising relaxants should be used cautiously in patients receiving these drugs until definitive information is available about their interac. tions.

The points raised by $\mathrm{Dr}$. Donati are well taken. The actual total dose of atracurium administered was $85 \mathrm{mg}$ $\left(1.44 \mathrm{mg}^{\left.-\mathrm{kg}^{-1}\right)}\right.$ over the 2.5-hour procedure. This included $25 \mathrm{mg}$ initially followed by three additional doses of
$20 \mathrm{mg}$. Unfortunately, due to our error, the incorrect dosage was described in the case report. During the operation, the response of the adductor policis to unar nerve stimulation was assessed visually. In addition, contractions of the facial muscles in response to stimulation of the facial nerve were also assessed visually. Although, as pointed out by Dr. Donati, there may be differences between the sensitivities of various muscles to non-depolarizing blockers, our patient did not exhibit this phenomenon.

We recognize that even trained observers may overestimate the degree of contraction to nerve stimulation: however, we do not routinely use recording equiment in every patient who demonstrates muscle weakness at the conclusion of an anaesthetic. We agree that succinylcho. line, gentamycin, enflurane and d-tubocurarine can alter the response to atracurium and this was discussed in our report.

The last comment made by $\mathrm{Dr}$. Donati certainly is valid. We agree that all the necessary information could have been obtained by the responses to train-of-four stimulation and that we may have confused the picture by using tetanic $(100 \mathrm{~Hz})$ stimulation. Even if train-of-four responses are assessed prior to tetanic stimulation, post-tetanic potentiation may persist for a long time. Train-of-four response provides information about the degree of neuromuscular block, but up to 70 per cent of receptors have to be blocked before fade becomes evident. To assess the degree of recovery from block this information may not be sufficient and a normal response to tetanic stimulation $(100 \mathrm{~Hz})$ is more reassuring. We recognize that post-tetanic distortion of twitch may be prolonged and may lead one to overestimate recovery from blockade.

In spite of all the complicating factors, we believe that this patient was weak due to atracurium, particularly when we consider that only $85 \mathrm{mg}\left(1.44 \mathrm{mg} \cdot \mathrm{kg}^{-1}\right)$ were used during the $2.5 \mathrm{hr}$ operation and no supplemental dose was administered in the last $30 \mathrm{~min}$.

Marina D. Bizzarii-Schmid MD

Sukumar P. Desai MD

Department of Anesthesia

Harvard Medical School

Brigham and Women's Hospital

Boston, MA 02115

\section{REFERENCES}

1 Goodman A, Gilman A. The Pharmacological Basis of Therapeutics, Ed 6, Macmillan Publishing Co., Inc., New York 1980 pp. 1304-5, 1432, 1438 1456, 1481.

2 Professional Information Brochure. Nolvadex (Tamoxifen Citrate). Stuart Pharmaceuticals Division of ICI Americas Inc., Wilmington, Delaware 19897. Revised December 1984.

3 Professional Information Brochure. Danocrine (Brand of Danazol Capsules, USP), WinthropBreon, Division of Sterling Drug, Inc. New York, NY 10016. Revised September 1985. 